\title{
NECESSARY CONDITIONS FOR SOLVING INITIAL VALUE PROBLEMS WITH INFIMA OF SUPERFUNCTIONS
}

\author{
RODRIGO LóPEZ POUSO
}

Abstract. Goodman proved that the pointwise infimum of all superfunctions is the minimal absolutely continuous solution of

$$
x^{\prime}=f(t, x), \quad t \in[0,1], x(0)=0,
$$

in case $f$ is a $L^{1}$-bounded Carathéodory function. How far can Carathéodory conditions be weakened without loosing that property? First we establish necessary conditions over $f$ for Goodman's method to be valid, and then we use them as a starting point to deduce sufficient ones. In this way we obtain new existence results and we provide new insights concerning the application of Goodman's method.

Mathematics subject classification (2000): 34A12, 34A36, 34A40.

Key words and phrases: subfunctions, superfunctions, discontinuous differential equations.

\section{REFERENCES}

[1] P. A. Binding, D. C. Biles, On Carathéodory's conditions for the initial value problem, Proc. Amer. Math. Soc. 125, (1997), 1371-1376.

[2] D. C. BILES, E. SCHECHTER, Solvability of a finite or infinite system of discontinuous quasimonotone differential equations, Proc. Amer. Math. Soc. 128, 11 (2000), 3349-3360.

[3] G. S. Goodman, Subfunctions and the initial-value problem for differential equations satisfying Carathéodory's hypotheses, J. Differential Equations, 7, (1970), 232-242.

[4] P. R. Halmos, Measure theory, Van Nostrand Reinhold Company, New York, 1950.

[5] E. R. HASSAN, W. RZYMOWSKI, Extremal solutions of a discontinuous differential equation, Nonlinear Anal. 37, (1999), 997-1017.

[6] E. J. MCShane, Integration, Princeton University Press, Princeton, 1967.

[7] G. Peano, Sull'integrabilità delle equazioni differenzialli di primo ordine, Atti. Accad. Sci. Torino, 21, (1885), 677-685.

[8] R. L. Pouso, On the Cauchy problem for first order discontinuous ordinary differential equations, J. Math. Anal. Appl., 264, (2001), 230-252. 